\title{
Sem promessas: a fala dos candidatos
}

E um tempo de promessas. Elas chegam pelo rádio, pela TV, povoam os palanques.

Mas, nem todos os candidatos sintonizam essa freqüência. Alguns preferem o debate livre e franco. LN traz nesta edição os depoimentos de dois candidatos a prefeituras das capitais: Eduardo Suplicy (do PT de São Paulo), entrevistado por Edison Nunes e Marllia Garcia, e Edson Andrino (do PMDB de Florianopolis), entrevistado por Lúcio Kowarick, Paulo J. Krischke e Edison Nunes.

Originalmente, LN tentou realizar um debate, com vários candidatos, de diferentes partidos, de diferentes estados. Mas, até a última hora, os senadores Saturnino Braga (PDT-RJ) e Fernando Henrique Cardoso (PMDB-SP) não confirmaram suas presenças. $E$, no último instante, o deputado Roberto Freire (PCB-PE) desmarcou a sua participação.

\section{Eduardo Suplicy}

MARÍLIA - $O$ prefeito que for eleito em 15 de novembro vai ter de assumir a condução de uma máquina, burocrática e administrativa, totalmente emperrada por hábitos de décadas. São práticas relacionadas ao clientelismo, à centralização de recursos que emperram as açôes mais ágeis e democráticas. Que politica é possivel fazer nesse quadro?

SUPLICY - Nós vamos ter de fazer uma adaptação da atual máquina administrativa. A prefeitura de São Paulo tem quase $110 \mathrm{mil}$ funcionários, e as pessoas que estão empregadas no poder público têm de ter ciência de que precisam trabalhar de acordo com a vontade popular.
Primeiro, nós teremos de ter um diálogo com as entidades representativas do funcionalismo e reconhecer, na prática, essas entidades.

Mas, mais que tudo, nós vamos precisar cortar alguns cordð̋es umbilicais que existem entre essa máquina administrativa e o conjunto de empresas particulares que costumam prestar serviços, vender bens e estabelecer contratos com a prefeitura. Muitas vezes, dado o relacionamento de longo prazo que existe entre essas empresas e o poder público, elas se organizam de tal forma que chegam até mesmo a direcionar as prioridades governamentais.

A prefeitura se relaciona com a iniciativa privada em diversos aspectos. Em primeiro lugar, a questão do meio ambiente que, embora seja 
mais afeta ao Estado, nós precisamos nos preocupar com isso, porque é obrigação da prefeitura fazer com que o Estado aja adequadamente nessa área. É preciso ter uma fiscalização e uma legislação de tal forma que controle a instalação de empresas na cidade, para que elas não destruam e venham até a recuperar o que foi destruído no meio ambiente da cidade.

A prefeitura, por outro lado, é compradora de bens e serviços. E na hora de definir - o mais democraticamente possível, de acordo com os interesses da população - 0 que comprar, o que contratar, ela tem de ter um processo de concorrência o mais aberto possível. $O$ que tem ocorrido, mais freqüentemente, é que as concorrências públicas funcionam como um jogo de cartas marcadas. E preciso abrir o máximo a informação sobre as concorrências para que todas as empresas interessadas possam participar e os resultados sejam mais favoráveis ao interesse da população.

Também na sua relação com a iniciativa privada, a prefeitura tem de estar atenta à questão do emprego. No que diz respeito à seleção e promoção de funcionários, ela deve agir sempre através de concursos públicos, através de procedimentos abertos de tal forma que todos saibam os critérios de seleção, treinamento e promoção das pessoas.

Ainda com relação ao emprego, na hora de se definir obras é preciso tentar escolher aquelas que, com um mesmo volume de recursos, impliquem a criação de maiores oportunidades de emprego.
MARÍLIA - Mas como, efetivamente, quebrar esse cordão umbilical a que você se referiu?

SUPLICY - Justamente através de métodos democráticos, que façam as prioridades governamentais serem definidas em primeiro lugar pela população, pelo interesse público. Não basta falar de um governo de participação popular, se nós não criarmos os instrumentos dessa participação. Quais são esses instrumentos?

De um lado, estão os instrumentos naturais de organização, o movimento popular, que precisa ser ouvido com muita atenção. É preciso criar canais para que esses movimentos participem, não apenas daquilo que eles estão reivindicando diretamente, para que eles ganhem uma perspectiva do que está sendo prioritário no conjunto das açס̃es definidas pelo governo.

Além de convidarmos os movimentos, a Câmara Municipal, o funcionalismo e outros segmentos da sociedade a participarem da definição de prioridades e da elaboração do orçamento, nós também vamos criar alguns instrumentos para possibilitar a maior participação institucional. Um deles será a eleição direta dos administradores regionais da cidade de São Paulo.

A eleição do administrador regional não significa qualquer enfraquecimento do poder do prefeito. Ao contrário, significa um respeito dele pelas necessidades de cada região da cidade. São Paulo é uma cidade com 10 milhres de habitantes. A região metropolitana, a Grande São Paulo, tem 38 milhões de habitantes. São vários municí- 
pios, alguns ainda menores do que algumas das regióes administrativas do município de São Paulo, que são governados por diferentes prefeitos. Então, é perfeitamente viável que o prefeito de São Paulo dê autonomia às regióes administrativas e passe a trabalhar com uma coordenação das regionais. Mesmo que, em algumas delas, tenhamos administradores eleitos por outros partidos.

Esses administradores regionais eleitos diretamente estarão subordinados ao prefeito no que diz respeito às decisð̃es maiores para a cidade; deverão seguir as diretrizes do prefeito. Mas, por outro lado, se eventualmente forem de partidos diferentes, eles naturalmente estarão tendo acesso ao que faz a administração pública e estarão fiscalizando continuamente a administração do prefeito. E isso eu acho saudável. Eu terei de estabelecer normas iguais para os 17 administradores, e essa é uma forma de tornar a administração muito mais transparente.

O segundo instrumento importante para essa maior participação é a eleição direta, em cada uma das regionais, de um conselho de representantes do povo. Esses representantes não seriam remunerados e se reuniriam, numa frequiência determinada por eles mesmos, para ajudar na determinação das prioridades, em nível regional, no nível da prefeitura e até dos debates a serem travados na Câmara de Vereadores.

Esse conselho significará um fortalecimento e um canal adicional para a atuação das associaçð̃es de moradores, de bairros, que poderão se comunicar melhor e, eventualmente, lançar candidatos para o conselho.

Esses são caminhos bastante democráticos para neutralizar aquele cordão umbilical a que eu me referia.

MARÍLIA - Um tema recorrente, nos discursos dos vários candidatos, é a questão da autonomia municipal. E, fatalmente, esse tema é relacionado à questão da reforma tributária. Qual a sua proposta para esse tema?

SUPLICY - E fundamental que a ampliação da autonomia do município com relação ao estado e à União seja realizada. Veja que, dos tributos e fundos (FGTS, PIS, PASEP) arrecados na cidade de São Paulo, o que volta para ser alocado na cidade é muito pouco, talvez menos de $10 \%$.

Se nós tomarmos os orçamentos do município de São Paulo, do estado e da União e dividirmos pelo número de habitantes, vamos ver que, enquanto o estado e a União têm, cada um, cerca de três salários mínimos por habitante para gastar, a prefeitura dispõe apenas de dois salários mínimos por habitante!

Eu acho que a prefeitura tem de ter uma participação maior sobre a decisão do que deve ser feito com o dinheiro arrecadado na cidade. $\mathrm{E}$ a reforma tributária tem de caminhar na direção de dar, ao próprio município, maior autonomia de decisão sobre como e o que gastar desse bolo todo. Isso, certamente, deverá ser tema da Constituinte.

EDISON - Cidades como São 
Paulo estão cada vez mais inseridas numa dinâmica regional que torna dificil pensá-las fora do contexto da metrópole. Como é que você pensa a relação da autonomia municipal com a questão das regioes metropolitanas?

SUPLICY - Ao mesmo tempo que se deve ter uma maior autonomia municipal, é preciso buscar mecanismos de colaboração e coorde- nação com os municípios vizinhos. Especialmente no que diz respeito a transportes coletivos, é preciso haver uma maior cooperação e uniformidade dos serviços. O metrô deve chegar a toda a região metropolitana. É importante desenvolvermos uma colaboração maior para a administração conjunta de tudo aquilo que envolve a coordenação de esforços para objetivos comuns. $\star$

\section{Edson Andrino}

PAULO K. - Para podermos entender melhor o caso de Santa Catarina, como se situa a sua candidatura, diante das outras forças políticas do estado?

ANDRINO - Quem manda em Santa Catarina são as famílias Ramos e Bornhausen, que antes de 1964 eram, respectivamente, UDN e PSD. Depois da revolução, com a criação dos novos partidos, as duas famílias se juntaram na ARENA, e o MDB passou a ser a grande esperança do povo catarinense.

Em 1982, essas duas famílias estavam encontrando dificuldade em se manterem juntas no PDS e acabaram buscando em Esperidião Amin a sua tábua de salvação. Era uin rapaz novo, que não tinha vinculação partidária anterior, com una preocupação política e administrativa diferente, que aceitou essa aliança com as duas oligarquias.

Com o aparecimento da Aliança Democrática, as oligarquias se reciclaram em Santa Catarina. Os Ramos e os Bornhausen foram para a Erente Liberal. E tornaram extremamente difícil, para nós, que fazemos política no PMDB há 20 anos, a convivência com a Frente Liberal na Aliança Democrática.

E nós, que sempre defendemos as antigas grandes bandeiras do partido - Assembléia Nacional Constituinte, eleições diretas para presidente da República, contra a Lei de Segurança Nacional -, bandeira que estamos tentando segurar a todo custo, vemos o partido se descaracterizar, ao se aliar com a Frente Liberal.

Nesse quadro, o senador Jaison Barreto, que tinha a proposta mais avançada do PMDB, acabou se aliando com o governador Espiridião Amin, que lançou um candidato malufista à prefeitura de Florianópolis.

PAULO K. - $A$ aliança é feita por quem? PDS mais o quê?

ANDRINO - É pessoal. É uma aliança Jaison-Amim, sem ouvir os partidos. E uma coisa complicada.

Então, eu, como candidato, tenho o apoio de um segmento do PT (um grupo que foi marginalizado dentro do Partido dos Trabalha- 
dores) e da esquerda mais independente do PMDB. Não temos vinculação com outros partidos de esquerda, combatemos a Aliança Democrática e seguramos as bandeiras tradicionais do partido.

Nós enfrentamos, na convenção, o companheiro Nelson Pelegrino, que defende a Aliança Democrática e acabou até admitindo uma aliança com o senador Jorge Bornhausen. Mas parece que não é isso que o povo catarinense quer. Todas as pesquisas em Santa Catarina mostram que o povo não admite uma aliança do PMDB com a Frente Liberal nem com o PDS.

NUNES $-A$ estrutura atual da prefeitura de Florianópolis é uma máquina com uma série de problemas, com respeito aos recursos $e$ mesmo à própria autonomia do município. Como você está diagnosticando esse quadro e o que poderia ser feito para superá-lo?

ANDRINO - Não apenas em Florianópolis, mas em todos os municípios do Brasil, tudo passa pela situação financeira. É exatamente aí que está a importância de se fazer uma reforma tributária agora.

A prefeitura de Florianópolis tem em torno de 4000 funcionários, e a arrecadação do município não chega nem a cobrir a folha de pagamento. É uma cidade que não tem indústria, vive em função do turismo e do comércio, que é pequeno. Ela é a capital do estado e ali está toda a máquina administrativa dos governos estadual e federal. Cerca de $80 \%$ dos seus moradores são funcionários públicos.

Apesar disso tudo, Florianópolis não cumpre plenamente a sua função de capital do estado. As grandes empresas nacionais de origem catarinense, nenhuma delas tem escritório central em Florianópolis. Operam seus negócios com o resto do pais, às vezes, a partir de Curitiba ou Porto Alegre. Nós queremos trabalhar para que Florianópolis se valorize como capital e para que todos os fatos econômicos, culturais e políticos passem obrigatoriamente por ela.

Além disso, nós precisamos trabalhar para que se faça uma reforma tributária municipal que adapte a cobrança do imposto predial e territorial à realidade do uso e do tamanho dos imóveis. Hoje, em Florianópolis, pelo menos $40 \%$ da população não paga IPTU, ou porque são entidades do Estado, ou por acertos com as oligarquias que sempre dominaram o ramo de imóveis e a prefeitura.

O importante é que se faça logo uma reforma tributária nacional que aumente os recursos dos municípios, para que a gente possa ter criatividade e ouvir a comunidade. Essa é a nossa proposta básica para administrar.

NUNES - Na prática, como você pretende ouvir a comunidade $e$, a partir disso, de que maneira serão escalonadas as prioridades administrativas?

ANDRINO - Vamos criar mecanismos para ajudar a comunidade a se organizar. A comunidade precisa se organizar de forma essencialmente crítica, com muita independência dos partidos e da prefeitura. 
Em Santa Catarina, já existe uma estrutura de participação que pode ser aproveitada: são os conselhos comunitários. Apenas, é preciso modificar uma das características atuais, que é limitante: a obrigatoriedade de o presidente do conselho ter seu nome homologado pelo governador do estado.

Paralelamente a isso, a gente está tentando criar novas associações de moradores que sejam muito independentes. Eu insisto na questão da independência porque a comunidade tem de estar organizada para, no futuro, ter força para se confrontar com qualquer outro governo que assuma, para cobrar obras e propostas em favor do povo.

Queremos também usar as organizações que já existem: as colônias de pescadores artesanais, onde os presidentes são eleitos diretamente pelos pescadores, a OAB, os sindicatos, as associaçzes de moradores, os conselhos de Igrejas, os diretores de escola. Todos eles vão ajudar a administração. A comunidade sabe o que precisa.

KOWARICK - Que a população conhece os seus problemas cotidianos é verdade. Por exemplo, a população sabe que a linha de ônibus pode ser desta ou de outra forma. Mas, quando se trata de estabelecer uma politica para o planejamento dos transportes da cidade, a questão passa a ser geral e exige mais que o conhecimento dos problemas locais. Considerando isso, a sua visão é mais no sentido de tornar a máquina do Estado mais simples ou, mais do que isso, no sentido de que a comunidade deve aos poucos ir participando dos processos estratégicos?

ANDRINO - A realidade de Florianópolis é muito diferente da realidade de São Paulo. A praticidade dessa proposta de ouvir a comunidade é mais possível em Santa Catarina. E claro que a prefeitura tem de participar ativamente da discussão e da elaboração de uma proposta. Mas isso tem de passar pela comunidade.

Por exemplo, o caso do transporte coletivo. A comunidade de cada bairro sabe onde é importante o ônibus parar e passar. Hoje, quem estabelece o horário dos ônibus é a prefeitura junto com o empresariado. A comunidade tem de participar disso.

No nosso caso, a questão mais grave é a da tarifa social. Em Florianópolis, nos fins de semana, vigoram "preços especiais" para as tarifas de ônibus. Em certas linhas, esses preços são até três vezes mais altos que os preços nos dias úteis. Isso significa que, através do preço do ônibus, a prefeitura regula quais as praias que estão abertas à frequiência popular. Na hora de lazer, o trabalhador não tem direito de freqüentar as praias livremente, pois não tem acesso ao preço do transporte. Para se ter uma idéia, a praia de Jurerê, que era popular porque oferecia sombras e segurança para as crianças, deixou de ter serviços de ônibus no fim de semana, desde que uma grande construtora implantou ali um conjunto habitacional de elite.

Uma prefeitura consciente pode mudar essa situação irregular. $\quad \star$ 